\title{
Oxaliplatin plus leucovorin and 5-fluorouracil (FOLFOX-4) as a salvage chemotherapy in heavily-pretreated platinum-resistant ovarian cancer
}

\author{
Vincenza Conteduca ${ }^{1 *}$ (D), Giorgia Gurioli ${ }^{2}$, Lorena Rossi ${ }^{1}$, Emanuela Scarpi ${ }^{3}$, Cristian Lolli ${ }^{1}$, Giuseppe Schepisi ${ }^{1}$, \\ Alberto Farolfi ${ }^{1}$, Delia De Lisii ${ }^{4}$, Valentina Gallà ${ }^{1}$, Salvatore Luca Burgio ${ }^{1}$, Cecilia Menna ${ }^{1}$, Andrea Amadori ${ }^{5}$, \\ Lorena Losi ${ }^{6}$, Dino Amadori ${ }^{1}$, Maria Paola Costi ${ }^{6}$ and Ugo De Giorgi ${ }^{1}$
}

\begin{abstract}
Background: The purpose of this study was to evaluate the clinical impact of oxaliplatin, leucovorin, and 5fluorouracil (FOLFOX-4) chemotherapy in terms of the response rate, progression-free/overall survival (PFS/OS) and safety profile in patients with heavily pretreated recurrent epithelial ovarian cancer.

Methods: Clinical data were reviewed in 29 patients who received FOLFOX-4 as more than third-line chemotherapy, consisting of $85 \mathrm{mg} / \mathrm{m}^{2}$ of oxaliplatin, $200 \mathrm{mg} / \mathrm{m}^{2}$ of leucovorin, and bolus $400 \mathrm{mg} / \mathrm{m}^{2}$ on day 1 of 5 -fluorouracil, followed by a 22 -h infusion of $600 \mathrm{mg} / \mathrm{m}^{2}$ of 5 -fluorouracil for 2 consecutive days every 3 weeks. We also compared the efficacy and toxicity of FOLFOX-4 with that of topotecan, a standard treatment, given at a dosage of $1.5 \mathrm{mg} / \mathrm{m}^{2}$ every three weeks in 26 patients.

Results: The median age of enrolled patients was 60 years (range 33 to 85). A median of 4 cycles (range 1-17) of FOLFOX-4 were administered. Complete response and partial response were observed in one (3.5\%) and 5 (17.2.2\%) patients, respectively, while stable disease was reported in 8 (27.6\%) patients. Among all patients, grade 3-4 anemia, neutropenia, and thrombocytopenia were observed in $0(0 \%), 5(17.2 \%)$, and $3(10.3 \%)$ cases, respectively. Grade 3-4 fatigue was recorded in one (3.4\%) patient and diarrhea in 2 (6.9\%). Median PFS and OS were 2.8 months [95\% confidence interval (Cl) 1.7-4.9] and 6.2 months (95\% Cl 2.4-14.6), respectively. No significant differences in terms of efficacy and toxicity were observed between patients receiving FOLFOX-4 and those treated with topotecan.
\end{abstract}

Conclusions: The FOLFOX-4 regimen would seem to obtain similar survival rates to those of standard therapy with topotecan in platinum-resistant ovarian cancer. Further randomized trials are warranted to confirm our findings.

Keywords: FOLFOX-4, Fluorouracil, Topotecan, Ovarian cancer, Platinum resistance, Survival

\section{Background}

Ovarian cancer remains a highly lethal malignancy, representing the sixth leading cause of cancer death in women and the most lethal gynecologic malignancy $[1,2]$. The prognosis for advanced ovarian cancer has improved over the last 10 years, especially thanks mainly to the

\footnotetext{
* Correspondence: cinzia.conteduca@libero.it

${ }^{1}$ Medical Oncology Department, Istituto Scientifico Romagnolo per lo Studio e la Cura dei Tumori (IRST) IRCCS, Via Piero Maroncelli 40, 47014 Meldola, FC, Italy

Full list of author information is available at the end of the article
}

introduction of more personalized therapeutic strategies. However, despite the high response rate to the standard carboplatin-paclitaxel first-line combination, most patients develop recurrent disease, with a median survival ranging from 12 to 24 months. Patients who progress on cisplatin or carboplatin or who relapse within 6 months of the end of treatment show the poorest outcome [2]. Single-agent therapies for platinum-refractory/resistant patients include oral etoposide, taxanes, topotecan, gemcitabine, vinorelbine, liposomal doxorubicin, and oxaliplatin, with response rates of around $15-20 \%$ and an overall survival (OS) of less than

(c) The Author(s). 2018 Open Access This article is distributed under the terms of the Creative Commons Attribution 4.0 International License (http://creativecommons.org/licenses/by/4.0/), which permits unrestricted use, distribution, and reproduction in any medium, provided you give appropriate credit to the original author(s) and the source, provide a link to the Creative Commons license, and indicate if changes were made. The Creative Commons Public Domain Dedication waiver (http://creativecommons.org/publicdomain/zero/1.0/) applies to the data made available in this article, unless otherwise stated. 
12 months [3]. Research is now aiming to improve chemotherapy, identify novel, effective and well-tolerated agents, and overcome platinum resistance.

Cisplatin and carboplatin are the most common platinum compounds used to treat ovarian cancer. Oxaliplatin, a diaminocyclohexane platinum compound, has a different spectrum of activity and toxicity to that of other platinum agents and does not usually show cross-resistance with cisplatin and carboplatin in ovarian cancer $[4,5]$. In previous phase II studies, oxaliplatin at a dose of $130 \mathrm{mg} / \mathrm{m}^{2}$ every 3 weeks was administered to patients with cisplatin- or carboplatin-refractory/resistant and taxane-pretreated ovarian cancer, obtaining response rates of $4.3-29.0 \%$ and a median OS of 9.5-15 months [6-9]. The combination of 5 -fluorouracil with leucovorin given as intravenous bolus or continuous infusion has also been used to treat platinum-resistant/recurrent ovarian cancer but has shown limited clinical activity [10-14].

Some in vitro studies indicate a potential synergy between oxaliplatin and 5-fluorouracil/leucovorin [15]. The combination of these drugs (called FOLFOX) represents a standard chemotherapeutic regimen in the management of some advanced tumours [16-18]. Preliminary data on the use of this treatment in recurrent ovarian cancer have not been entirely satisfactory/have not been encouraging [19-22]. In the present study we evaluated the efficacy, in terms of clinical outcome, and toxicity of FOLFOX-4 in platinum-resistant ovarian cancer. In addition, through an exploratory analysis, we compared our results with data from patients treated with topotecan, a drug usually administered alone as salvage chemotherapy in platinum-resistant disease.

\section{Methods}

\section{Study population}

We retrospectively evaluated 29 patients treated with the FOLFOX-4 regimen from February 2008 to April 2016 as the primary cohort, and 26 patients treated with topotecan between August 2010 and December 2014 as the secondary cohort. Eligibility criteria of both cohorts were histological confirmation of epithelial ovarian cancer, previous treatment with cisplatin or carboplatin plus paclitaxel regimens, and disease recurrence during treatment with or within 6 months of the end of the cisplatin or carboplatin-based chemotherapy. Additional eligibility criteria included Eastern Cooperative Oncology Group (ECOG) performance status $0-2$, and adequate cardiac, renal, hepatic and bone marrow function. Metastatic disease was documented by bone scan, computed tomography or magnetic resonance imaging. The retrospective study was approved by the Institutional Review Board of Istituto Scientifico Romagnolo per lo Studio e la Cura dei Tumori (IRST) IRCCS and was conducted in accordance with the ethical standards laid down in the 1964
Declaration of Helsinki. The need for written informed consent from participants was waived because of the retrospective nature of the research.

Patients were evaluated for safety and dosing compliance every 2 weeks for the first 3 months of chemotherapy, and then monthly thereafter until treatment discontinuation. Renal, liver and bone marrow function were assessed at every cycle, while cancer antigen 125 (CA-125) and radiographic evaluation were left to the discretion of the treating physician, but were usually performed after at least three months' treatment.

\section{Treatment and evaluation}

Treatment with FOLFOX-4 consisted of $85 \mathrm{mg} / \mathrm{m}^{2}$ of oxaliplatin as a 2 -h infusion on day $1,200 \mathrm{mg} / \mathrm{m}^{2}$ of leucovorin as a 2 -h infusion on day 1 , and bolus $400 \mathrm{mg} / \mathrm{m}^{2}$ of 5-fluorouracil on day 1 , followed by a 22 -h infusion of $600 \mathrm{mg} / \mathrm{m}^{2}$ of 5 -fluorouracil for two consecutive days every three weeks. Topotecan was administered at a dosage of $1.5 \mathrm{mg} / \mathrm{m}^{2}$ by intravenous infusion daily for 5 consecutive days, starting on day 1 of a 21-day course. Both therapeutic regimens were administered continuously until there was evidence of either progressive disease (PD) or unacceptable toxicity. Prophylactic granulocyte-colony stimulating factor was only permitted for patients who developed grade 3-4 neutropenia or febrile neutropenia.

Tumor response was evaluated every three cycles by repeating baseline assessments using imaging studies (computed tomography and/or magnetic resonance imaging) according to the Response Evaluation Criteria in Solid Tumors (RECIST) for patients with measurable disease [23]. CA-125 was evaluated in recurrent disease using CA-125 response criteria developed by the Gynecologic Cancer InterGroup [24]. Toxicity was graded using the National Cancer Institute Common Terminology Criteria for Adverse Events (CTCAE), version 4 [25].

\section{Statistical analysis}

All data were analyzed by descriptive statistics. Relationships between patient characteristics were testing using the Chi-square test for categorical variables and the median test for continuous variables. The Kaplan-Meier method was used to estimate PFS and OS, with two-sided 95\% confidence intervals (95\%CI). PFS was defined as the time from the start of FOLFOX-4 or topotecan until disease progression or last tumor evaluation or death from any cause. OS was defined as the time from the start of FOLFOX-4 or topotecan until death from any cause or last follow-up. Survival curves were compared using the log-rank test. Due to exploratory intent, no multiple testing correction was performed. All statistical analyses were carried out with SAS statistical software, version 9.4 (SAS Institute, Cary, NC, USA). A two-sided $P$-value $<0.05$ was deemed statistically significant for all the analyses. 


\section{Results}

\section{Patient characteristics}

The median age was significantly different in the FOLFOX-4 and topotecan populations (60years [range 33-85] and 66 years [range $51-80])$, respectively $(P=0.032)$. FOLFOX-4treated patients showed a higher incidence of abdominal and extra-abdominal metastases (18 [62.1\%] vs. 6 [23.1\%]) $(P=0.004)$. All patients had previously received a median of 4 (range 1-17) and 3 (range 1-8) cycles of FOLFOX-4 and topotecan, respectively $(P=0.038)$. Fourteen $(48.3 \%)$ and 6 (23.1\%) patients had received more than 4 treatments before FOLFOX-4 and topotecan, respectively $(P=0.055)$, whose 2 (range, 1-4) including a platinum-based treatment in both FOLFOX-4 and topotecan groups. Among FOLFOX-4 patients receiving a prior platinum-based treatment, we reported a recurrent and refractory disease in 19 (65.5\%) and 10 (34.5\%) patients, respectively, whilst we observed a recurrent and refractory cancer in 17 (64.4\%) and 9 (35.6\%), respectively, in the topotecan-treated patients. In the FOLFOX-4 group, a prior treatment with topotecan was reported in $4(13.8 \%)$ patients, and only one $(3.8 \%)$ patient received a prior therapy with FOLFOX-4 in the topotecan group. Among pre-treatment laboratory parameters, the incidence of neutrophil-to-lymphocyte ratio (NLR) $\geq 3$ was significantly higher in patients treated with FOLFOX-4 than in those receiving topotecan (15 [53.6\%] vs. 7 $[28.0 \%])(P=0.013)$. Patient characteristics are summarized in Table 1.

\section{Treatment outcomes}

All patients treated with FOLFOX-4 and topotecan chemotherapy had measurable disease and were evaluable for tumor response by RECIST criteria (Table 2). Of the 29 patients treated with FOLFOX-4, 1 (3.5\%) showed a complete response (CR), 5 (17.2\%) a partial response (PR) and $8(27.6 \%)$ stable disease (SD). Of the 26 topotecan patients, $1(3.8 \%)$ had a CR, $1(3.8 \%)$ a PR and 6 (23.1\%) SD. Objective response was assessed by Rustin et al.'s [25] CA-125 criteria using the baseline CA-125 value as reference. Five patients treated with FOLFOX-4. and 8 with topotecan were not evaluable by Rustin's CA-125 criteria. A CA-125 response was observed in 11 (44.0\%) FOLFOX-4 patients and 5 (26.3\%) topotecan patients (Table 2). The decrease in CA-125 levels was consistent with and not influenced by ascitic drainage. However, an objective radiological response (CR or $\mathrm{PR}$ ) was not associated with CA-125 response. Median follow-up was 45 months (range 1-45) for patients treated with FOLFOX-4 and 57 months (range 1-57) for those receiving topotecan. The FOLFOX-4 group showed a median PFS and OS of 2.8 months (range 1.7-4.9) and 6.2 months (range 2.4-14.6), respectively. Topotecan patients had a median PFS and OS of 2.8 months (range 1.8-4.9) and 10.4 months (range 4.9-19.5), respectively (Table 2). A comparison of survival curves between the 2 treatment groups did not reveal a significant difference in PFS (Fig. 1) and OS (Fig. 2).

Univariate analysis did not identify any significant factors (including site of metastasis, previous treatment lines, baseline NLR and platelet-to-lymphocyte ratio [PLR]) that predicted PFS (Table 3) and OS (Table 4) within each treatment group and between patients treated with FOLFOX-4 and topotecan, with the exception of NLR, a significant predictor of OS in FOLFOX-4 $(P=0.013)$.

At the time of analysis, 1 (3.4\%) patient in the FOLFOX-4 group and $2(7.7 \%)$ in the topotecan group were still alive. After progression on FOLFOX-4 or topotecan, 16 (57.1\%) and $17(65.4 \%)$ patients, respectively, underwent new treatments (Table 2).

\section{Safety and tolerability}

The incidence of grade 3-4 toxicity, in particular myelotoxicity, was similar in patients treated with FOLFOX-4 and topotecan (Table 5). Ten (34.5\%) and 2 (7.7\%) patients reduced FOLFOX-4 and topotecan dosage due to chemotherapy-related adverse events, respectively. However, only 2 (6.9\%) undergoing FOLFOX-4 and 3 (11.5\%) receiving topotecan discontinued treatment because of unacceptable toxicity.

\section{Discussion}

Despite relatively high response rates to first-line platinum-based therapies for epithelial ovarian cancer, the majority of patients relapse and a number of treatment-related deaths have also been reported. New-generation chemotherapeutic drugs and biological agents, especially those targeting angiogenesis [26] and the nuclear enzyme poly-(ADP-ribose) polymerase (PARP) [27, 28 ], have recently been introduced into clinical practice, increasing the number of therapies available for relapsed or refractory disease. Consequently, patients with advanced ovarian cancer often undergo multiple chemotherapy courses in an effort to achieve long-term remission and maintain an acceptable quality of life. The main risk from using an increasing number of therapeutic agents is cumulative toxicity, especially myelotoxicity, which may influence subsequent treatments. Hence the need for new, effective and less toxic therapies in patients with recurrent and persistent disease after failure of chemotherapy.

In the present retrospective monoinstitutional study, we analyzed the results obtained in a population of ovarian cancer patients treated with FOLFOX-4 or standard topotecan monotherapy in terms of clinical impact on outcome and toxicity. The choice of therapy and dosing schedule was at the discretion of the treating physician, as was the possibility of initial dose reduction due to older age and poor performance status. Efficacy and safety were comparable in both regimens, with hematological toxicity the most frequent reason for dose reduction. Treatment 
Table 1 Patient Characteristics

\begin{tabular}{|c|c|c|c|}
\hline \multirow{3}{*}{ Median age, years (range) } & \multirow{2}{*}{$\begin{array}{l}\text { FOLFOX-4 }(n=29) \\
\text { N (\%) }\end{array}$} & \multirow{2}{*}{$\begin{array}{l}\text { Topotecan }(n=26) \\
N(\%)\end{array}$} & \multirow[t]{2}{*}{$P$} \\
\hline & & & \\
\hline & $60(33-85)$ & $66(51-80)$ & 0.032 \\
\hline \multicolumn{4}{|l|}{ Histology } \\
\hline Serous & $22(75.9)$ & $22(84.6)$ & \\
\hline Non-serous & $7(24.1)$ & $4(15.4)$ & 0.422 \\
\hline \multicolumn{4}{|l|}{ FIGO stage at presentation } \\
\hline$|-| \mid$ & $3(14.3)$ & $2(12.5)$ & \\
\hline III & $16(76.2)$ & $11(68.7)$ & \\
\hline IV & $2(9.5)$ & $3(18.8)$ & 0.529 \\
\hline Unknown/missing & 8 & 10 & \\
\hline \multicolumn{4}{|l|}{ Grade } \\
\hline । & $5(20.8)$ & $7(29.2)$ & \\
\hline$\|$ & $5(20.8)$ & $4(16.7)$ & \\
\hline III & $14(58.4)$ & $13(54.1)$ & 0.612 \\
\hline Unknown/missing & 5 & 2 & \\
\hline \multicolumn{4}{|l|}{ ECOG Perfomance status } \\
\hline $0-1$ & $27(93.1)$ & $25(96.1)$ & \\
\hline 2 & $2(6.9)$ & $1(3.9)$ & 0.622 \\
\hline \multicolumn{4}{|l|}{ Sites of metastasis } \\
\hline Only abdominal & $11(37.9)$ & $20(76.9)$ & \\
\hline Abdominal + extra-abdominal & $18(62.1)$ & $6(23.1)$ & 0.004 \\
\hline \multicolumn{4}{|l|}{ Number of involved sites } \\
\hline 1 & $4(13.8)$ & $5(19.2)$ & \\
\hline 2 & $10(34.5)$ & $10(38.5)$ & \\
\hline$\geq 3$ & $15(51.7)$ & $11(42.3)$ & 0.459 \\
\hline Median interval from initial diagnosis, months (range) & $47(11.5-248)$ & $40.4(9.7-1301)$ & 0.129 \\
\hline \multicolumn{4}{|l|}{ Lines of previous treatments } \\
\hline$\leq 4$ & $15(51.7)$ & $20(76.9)$ & \\
\hline$>4$ & $14(48.3)$ & $6(23.1)$ & 0.055 \\
\hline \multicolumn{4}{|l|}{ Number of treatment cycles } \\
\hline Median value (range) & $4(1-17)$ & $3(1-8)$ & 0.038 \\
\hline \multicolumn{4}{|l|}{ Baseline NLR } \\
\hline$<3$ & $13(46.4)$ & $20(80.0)$ & \\
\hline$\geq 3$ & $15(53.6)$ & $5(20.0)$ & 0.013 \\
\hline Unknown/missing & 1 & 1 & \\
\hline \multicolumn{4}{|l|}{ Baseline PLR } \\
\hline$<210$ & $13(46.4)$ & $18(72.0)$ & \\
\hline$\geq 210$ & $15(53.6)$ & $7(28.0)$ & 0.062 \\
\hline Unknown/missing & 1 & 1 & \\
\hline Median baseline $\mathrm{Hb}, \mathrm{g} / \mathrm{dL}$ (range) & $11.1(8.3-15.0)$ & $12.1(8.9-14.3)$ & 0.058 \\
\hline Median baseline Ca125, ng/mL (range) & $289.9(13.3-11,344.0)$ & $100.2(12.6-10,805.0)$ & 0.259 \\
\hline Median baseline BMI, kg/m² (range) & $23.88(15.24-32.04)$ & $23.16(19.53-30.30)$ & 0.345 \\
\hline
\end{tabular}

Abbreviation. BMI body mass index, ECOG Eastern Cooperative Oncology Group, FIGO International Federation of Gynecology and Obstetrics, FOLFOX-4 oxaliplatin, leucovorin, and 5-fluorouracil, $\mathrm{Hb}$ hemoglobin, $N L$, neutrophil-to-lymphocyte ratio, PLR platelet-to-lymphocyte ratio 
Table 2 Treatment outcome

\begin{tabular}{lll}
\hline & FOLFOX-4 $(n=29)$ & Topotecan $(n=26)$ \\
\hline Median follow-up, months (range) & $45(1-45)$ & $57(1-57)$ \\
Median PFS, months $(95 \% \mathrm{Cl})$ & $2.8(1.7-4.9)$ & $2.8(1.8-4.9)$ \\
Median OS, months $(95 \% \mathrm{Cl})$ & $6.2(2.4-14.6)$ & $10.4(4.9-19.5)$ \\
Tumor response, $n(\%)$ & & $1(3.8)$ \\
CR & $1(3.5)$ & $1(3.8)$ \\
PR & $5(17.2)$ & $6(23.1)$ \\
SD & $8(27.6)$ & $18(69.3)$ \\
PD & $15(51.7)$ & $5(26.3)$ \\
Ca125 response*, $n$ (\%) & $11(44.0)$ & $17(65.4)$
\end{tabular}

*According to Rustin's criteria

Abbreviations. $C R$ complete response, FOLFOX-4 oxaliplatin, leucovorin, and 5-fluorouracil, $n$ number, $P F S$ progression-free survival, $P D$ progressive disease, $P R$ partial response, $O S$ overall survival, $S D$ stable disease

discontinuation due to toxicity was rare. Despite dose limiting cumulative neurotoxicity of oxaliplatin-based therapy, only one case presented a grade 4 neurotoxicity, although grade 2 neurotoxicities had a negative impact on the quality of life in a few cases heavily pretreated with taxane- and platinum-based therapies.

In terms of response, our findings were comparable to those of other studies [19-22] on patients with measurable disease. Major limitations of this study were a small number of patients, the retrospective design, and the presence of mismatch of the cohorts related to a lack of randomization. We observed that NLR was the only prognostic factor in our patient cohort, as reported in a recent meta-analysis [29]. However, due to exploratory intent, no multiple testing correction was performed. Although adjustments for multiple comparisons can help control the study-wide falsepositive rate, for exploratory analyses it is more important to judge $P$ values cautiously than to try to formally determine their true significance level. Precise adjustment of $\mathrm{P}$ values and confidence intervals is often impractical in the context of exploratory research but can be useful for hypothesis-driven research.

Despite all these several limitations of this study, we showed similar treatment outcomes (PFS, OS, and CA-125

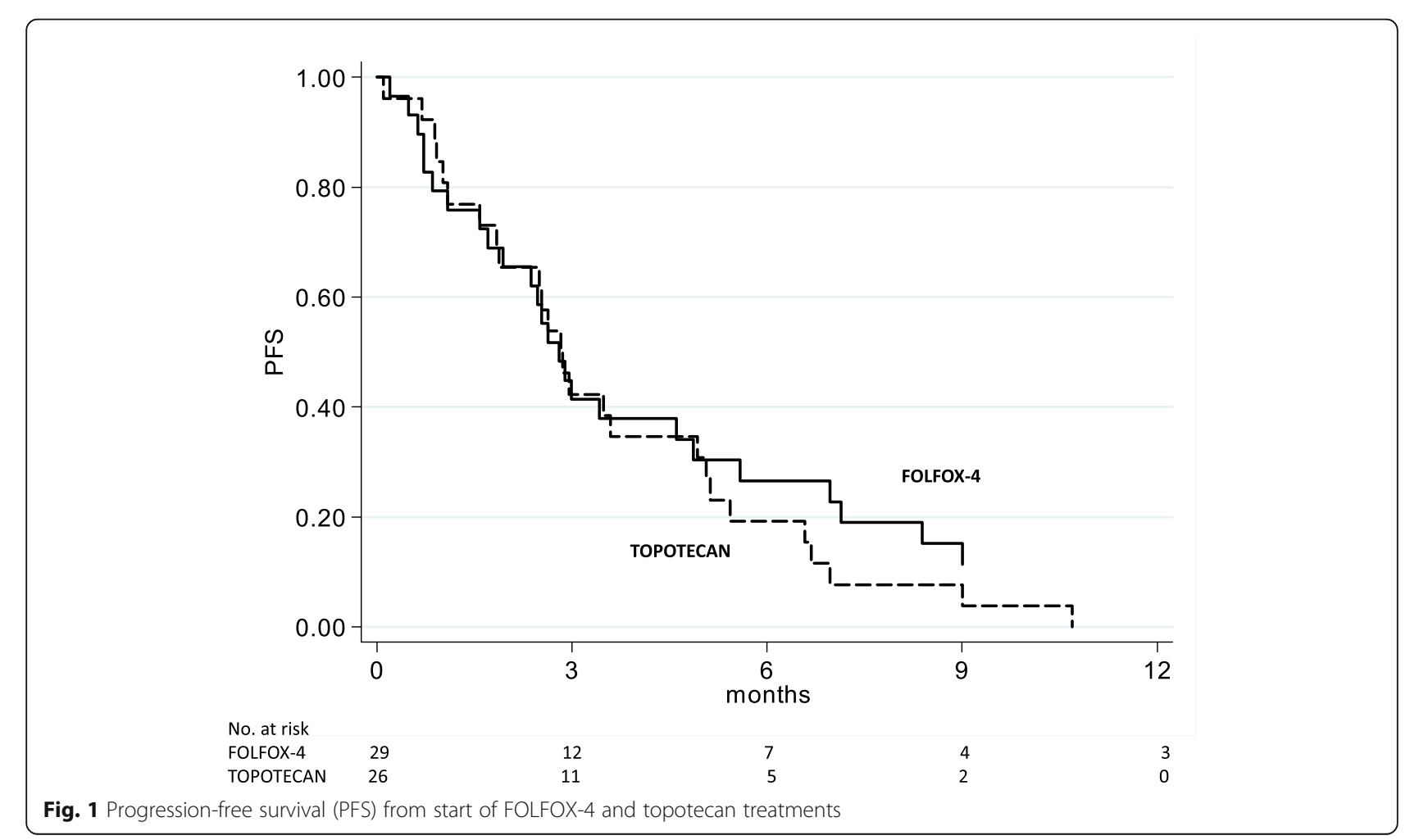




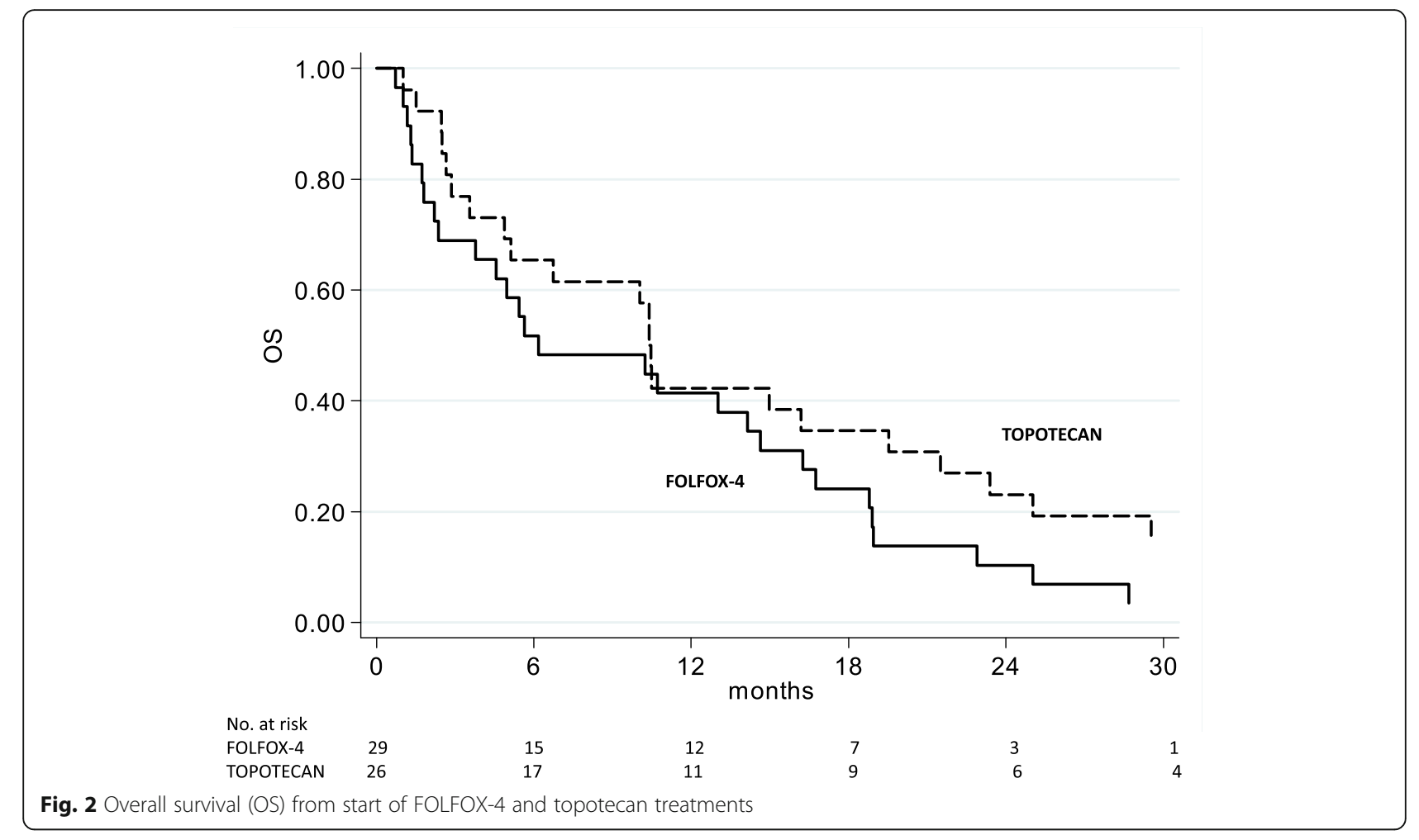

Table 3 Univariate subgroups analysis of progression-free survival

\begin{tabular}{|c|c|c|c|c|c|c|c|}
\hline & \multicolumn{3}{|l|}{ FOLFOX-4 } & \multicolumn{3}{|l|}{ TOPOTECAN } & \multirow[b]{2}{*}{$P$} \\
\hline & No. patients & No. events & Median PFS (95\% CI) & No. patients & No. events & Median PFS (95\% Cl) & \\
\hline \multicolumn{8}{|l|}{ Site of metastasis } \\
\hline Only abdominal & 11 & 10 & $2.8(0.6-5.6)$ & 20 & 20 & $2.7(1.1-3.6)$ & 0.617 \\
\hline Abdominal+extra-abdominal & 18 & 18 & $2.8(1.7-7.0)$ & 6 & 6 & $5.0(0.9-10.7)$ & 0.941 \\
\hline$P$ & & & 0.544 & & & 0.211 & \\
\hline \multicolumn{8}{|l|}{ Lines of previous treatments } \\
\hline$\leq 4$ & 15 & 15 & $2.6(0.6-4.6)$ & 20 & 20 & $3.2(1.6-5.4)$ & 0.948 \\
\hline$>4$ & 14 & 13 & $2.8(1.7-8.4)$ & 6 & 6 & $2.2(0.7-4.9)$ & 0.124 \\
\hline$P$ & & & 0.401 & & & 0.054 & \\
\hline \multicolumn{8}{|l|}{ Baseline NLR } \\
\hline$<3$ & 13 & 12 & $3.0(2.4-18.5)$ & 20 & 20 & $2.9(1.6-5.1)$ & 0.142 \\
\hline$\geq 3$ & 15 & 15 & $1.9(0.7-4.6)$ & 5 & 5 & $2.5(1.0-6.6)$ & 0.690 \\
\hline$P$ & & & 0.075 & & & 0.388 & \\
\hline \multicolumn{8}{|l|}{ Baseline PLR } \\
\hline$<210$ & 13 & 12 & $2.9(0.7-18.5)$ & 18 & 18 & $2.9(1.6-5.1)$ & 0.235 \\
\hline$\geq 210$ & 15 & 15 & $2.5(0.9-4.6)$ & 7 & 7 & $2.5(0.9-3.5)$ & 0.539 \\
\hline$P$ & & & 0.177 & & & 0.154 & \\
\hline
\end{tabular}


Table 4 Univariate subgroups analysis of overall survival

\begin{tabular}{|c|c|c|c|c|c|c|c|}
\hline & \multicolumn{3}{|l|}{ FOLFOX-4 } & \multicolumn{3}{|l|}{ TOPOTECAN } & \multirow[b]{2}{*}{$P$} \\
\hline & No. patients & No. events & Median PFS (95\% Cl) & No. patients & No. events & Median PFS (95\% Cl) & \\
\hline \multicolumn{8}{|l|}{ Site of metastasis } \\
\hline Only abdominal & 11 & 11 & $5.0(1.3-14.6)$ & 20 & 18 & $10.4(2.9-25.0)$ & 0.166 \\
\hline Abdominal+extra-abdominal & 18 & 17 & $8.2(2.4-16.7)$ & 6 & 6 & $12.7(2.7-23.4)$ & 0.919 \\
\hline$P$ & & & 0.771 & & & 0.492 & \\
\hline \multicolumn{8}{|l|}{ Lines of previous treatments } \\
\hline$\leq 4$ & 15 & 15 & $10.2(1.3-16.7)$ & 20 & 18 & $10.5(2.7-25.0)$ & 0.057 \\
\hline$>4$ & 14 & 13 & $5.5(2.4-14.6)$ & 6 & 6 & $10.4(2.9-16.2)$ & 0.789 \\
\hline$P$ & & & 0.753 & & & 0.206 & \\
\hline \multicolumn{8}{|l|}{ Baseline NLR } \\
\hline$<3$ & 13 & 12 & $14.6(3.8-22.9)$ & 20 & 18 & $10.4(4.9-23.4)$ & 0.870 \\
\hline$\geq 3$ & 15 & 15 & $5.4(1.2-10.2)$ & 5 & 5 & $2.9(1.5-15.0)$ & 0.858 \\
\hline$P$ & & & 0.013 & & & 0.051 & \\
\hline \multicolumn{8}{|l|}{ Baseline PLR } \\
\hline$<210$ & 13 & 12 & $13.0(1.8-18.9)$ & 18 & 16 & $10.5(4.9-23.3)$ & 0.514 \\
\hline$\geq 210$ & 15 & 15 & $5.6(1.3-14.1)$ & 7 & 7 & $10.0(1.5-15.0)$ & 0.660 \\
\hline$P$ & & & 0.275 & & & 0.061 & \\
\hline
\end{tabular}

Abbreviations. FOLFOX-4 oxaliplatin, leucovorin, and 5-fluorouracil; number; $C l$ confidence interval, $N L R$ neutrophils-to-lymphocyte ratio, $O S$ overall survival, $P L R$ platelet-to-lymphocyte ratio

response) between FOLFOX-4 and topotecan group. Specifically, there were fewer cases of PD (15 [51.7\%] vs.18 [69.3\%]) and a similar number of SD (8 [27.6\%] vs. 6 [23.1\%]) in FOLFOX-4 compared to topotecan patients. FOLFOX-4 could thus represent a potential alternative to standard chemotherapy, with a similar toxicity profile, in this patient setting. However, more recent studies [30] suggested different dose regimes of topotecan characterized by reduced number of side effects and thus this could alter the comparison of toxicities between FOLFOX-4 and topotecan profiles in our study.

The present study did not bring to light any clinical prognostic factors for PFS and OS in either treatment group, probably because of the small sample size and the lack of adequate patient selection. In addition, currently, there are no biomarkers able to improve the selection of patients candidates to FOLFOX-4 combination. Potential predictive biomarkers could derive from the analysis of homologous recombination deficiencies such as BRCA1/2 alterations, especially because they are of particular interest for platinum-based regimens. Therefore, future clinical trials in this disease setting could be supported by genomic and proteomic studies to identify prognostic factors associated with response to fluorouracil. The advances made in genetic and molecular biology could provide a valuable insight into the alterations underlying these types of ovarian cancer, and the relationship between the mechanism of action of fluorouracil and the subsequent downstream molecular pathways activated during tumorigenesis and disease progression.

Table 5 Toxicity in FOLFOX-4 and Topotecan cohorts

\begin{tabular}{|c|c|c|c|c|}
\hline & \multicolumn{2}{|c|}{ FOLFOX-4 $(n=29)$} & \multicolumn{2}{|c|}{ Topotecan $(n=26)$} \\
\hline & Grade $3 n(\%)$ & Grade $4 n(\%)$ & Grade $3 n(\%)$ & Grade $4 n(\%)$ \\
\hline Anemia & - & - & $2(7.7)$ & $1(3.8)$ \\
\hline Neutropenia & $3(10.3)$ & $2(6.9)$ & - & - \\
\hline Thrombocytopenia & $1(3.4)$ & $2(6.9)$ & $2(7.7)$ & $1(3.8)$ \\
\hline Fatigue & $1(3.4)$ & - & $1(3.8)$ & - \\
\hline Neurotoxicity & - & $1(3.4)$ & - & - \\
\hline Hepatotoxicity & - & - & $1(3.8)$ & - \\
\hline Diarrhea & $2(6.9)$ & - & - & - \\
\hline
\end{tabular}




\section{Conclusion}

The retrospective nature of our study and the small sample size do not allow for definitive conclusions to be drawn. However, our results provide further evidence that the FOLFOX-4 regimen may be as effective as standard monotherapies and could be proposed as an appropriate salvage treatment in refractory or resistant ovarian cancer. However, it should be appropriate to consider these heavily-pretreated patients as an ideal group for clinical trials; particularly given the success or emerging data of some newer classes of targeted therapies such as PARP inhibitors, antivascular drugs, dual antibody like molecules, antibody drug conjugates and so randomized multicenter trials comparing the FOLFOX-4 regimen, alone or, particularly, in combination with targeted therapy, are warranted to improve the standard of care in patients with heavily-pretreated disease.

\section{Abbreviations}

95\%Cl: 95\% confidence interval; CA-125: cancer antigen 125; CR: complete response; CTCAE: Common Terminology Criteria for Adverse Events; ECOG: Eastern Cooperative Oncology Group; FOLFOX-4: oxaliplatin plus leucovorin and 5-fluorouracil; NLR: neutrophil-to-lymphocyte ratio; OS: overall survival; PARP: poly(ADP-ribose) polymerase; PD: progressive disease; PFS: progression-free survival; PLR: platelet-to-lymphocyte ratio; RECIST: Response Evaluation Criteria in Solid Tumors; SD: stable disease

\section{Acknowledgements}

The authors wish to thank Gráinne Tierney for editorial assistance.

\section{Funding}

No funding was received for this study.

\section{Availability of data and materials}

The datasets used and/or analyzed during the current study are available from the corresponding author on reasonable request.

\section{Authors' contributions}

VC and UDG was involved in the conception of the study, acquisition and analysis of the data, and wrote the first draft of the manuscript. VC, GG, LR, $C L, G S, A F, D D L, S L B$ and $C M$ were responsible for data acquisition. UDG and DA were involved in the conception and design of the study. CV, ES and UDG contributed to data analysis and interpretation of data. VC, ES, VG, AA, $\mathrm{LL}, \mathrm{MPC}$ and UDG critically revised the manuscript for important intellectual content. VC and ES participated in analyzing the results and drafting the manuscript. All authors read and approved the final manuscript.

\section{Ethics approval and consent to participate}

This study was reviewed and approved by the Istituto Scientifico Romagnolo per lo Studio e la Cura dei Tumori (IRST) IRCCS Institutional Review Board Ethics Committee (REC 5485/2018). It was conducted in accordance with the ethical standards laid down in the 1964 Declaration of Helsinki, and all the patients provided written informed consent.

\section{Consent for publication}

Not applicable.

\section{Competing interests}

VC and UDG have received speaker honoraria or travel support from Astellas, Janssen-Cilag, Bayer, Ipsen and Sanofi-Aventis. The other authors have no relevant affiliations or financial involvement with any organization or entity with a financial interest in or financial conflict with the subject matter or materials discussed in the manuscript apart from those disclosed.

\section{Publisher's Note}

Springer Nature remains neutral with regard to jurisdictional claims in published maps and institutional affiliations.

\section{Author details}

${ }^{1}$ Medical Oncology Department, Istituto Scientifico Romagnolo per lo Studio e la Cura dei Tumori (IRST) IRCCS, Via Piero Maroncelli 40, 47014 Meldola, FC, Italy. ${ }^{2}$ Biosciences Laboratory, Istituto Scientifico Romagnolo per lo Studio e la Cura dei Tumori (IRST) IRCCS, Meldola, Italy. ${ }^{3}$ Unit of Biostatistics and Clinical Trials, Istituto Scientifico Romagnolo per lo Studio e la Cura dei Tumori (IRST) IRCCS, Meldola, Italy. ${ }^{4}$ Medical Oncology Department, Campus Bio-Medico University, Via Alvaro del Portillo 200, 00128 Rome, Italy. ${ }^{5}$ Division of Gynecologic Oncology, Department of Obstetrics and Gynecology, Morgagni-Pierantoni Hospital, Forli, Italy. ${ }^{6}$ Department of Life Sciences, University of Modena and Reggio Emilia, Via Campi 183, 41125 Modena, Italy.

Received: 14 September 2018 Accepted: 4 December 2018

Published online: 19 December 2018

\section{References}

1. Jemal A, Bray F, Center MM, Ferlay J, Ward E, Forman D. Cancer statistics, 2011. CA Cancer J Clin. 2011;61:69-90.

2. Hennessy BT, Coleman RL, Markman M. Ovarian cancer. Lancet 2009;17; 374(9698):1371-1382.

3. Pignata S, Cecere S, Du Bois A, Harter P, Heitz F. Treatment of recurrent ovarian cancer. Ann Oncol. 2017;8(Suppl 8):viii51-6.

4. Raymond E, Chaney SG, Taamma A, Cvitkovic E. Oxaliplatin: a review of preclinical and clinical studies. Ann Oncol. 1998;9:1053-71.

5. Rixe O, Ortuzar W, Alvarez M, Parker R, Reed E, Paull K, et al. Oxaliplatin, tetraplatin, cisplatin, and carboplatin: spectrum of activity in drug-resistant cell lines and in the cell lines of the National Cancer Institute's anticancer drug screen panel. Biochem Pharmacol. 1996;52:1855-65.

6. Chollet $\mathrm{P}$, Bensmaine MA, Brienza $\mathrm{S}$, Deloche $\mathrm{C}$, Curé $\mathrm{H}$, Caillet $\mathrm{H}$, et al. Single agent activity of oxaliplatin in heavily pretreated advanced epithelial ovarian cancer. Ann Oncol. 1996;7:1065-70.

7. Soulie P, Bensmaine A, Garrino C, Chollet P, Brain E, Fereres M, et al. Oxaliplatin/cisplatin (I-OHP/CDDP) combination in heavily pretreated ovarian cancer. Eur J Cancer. 1997;33:1400-6.

8. Piccart MJ, Green JA, Lacave AJ, et al. Oxaliplatin or paclitaxel in patients with platinum-pretreated advanced ovarian cancer: a randomized phase II study of the European Organization for Research and Treatment of Cancer gynecology group. J Clin Oncol. 2000;18:1193-202.

9. Fracasso PM, Blessing JA, Morgan MA, Sood AK, Hoffman JS. Phase II study of oxaliplatin in platinum-resistant and refractory ovarian cancer: a gynecologic group study. J Clin Oncol. 2003;21:2856-9.

10. Prefontaine M, Donovan JT, Powell JL, Buley L. Treatment of refractory ovarian cancer with 5-fluorouracil and leucovorin. Gynecol Oncol. 1996;61: 249-52.

11. Morgan RJ Jr, Speyer J, Doroshow JH, Margolin K, Raschko J, Sorich J, et al. Modulation of 5-fluorouracil with high-dose leucovorin calcium: activity in ovarian cancer and correlation with CA-125 levels. Gynecol Oncol. 1995;58: 79-85.

12. Look KY, Muss HB, Blessing JA, Morris M. A phase II trial of 5-fluorouracil and high-dose leucovorin in recurrent epithelial ovarian carcinoma. A Gynecologic Oncology Group Study Am J Clin Oncol. 1995;18:9-22.

13. Kamphuis JT, Huider MC, Ras GJ, Verhagen CA, Kateman I, Vreeswijk JH, et al. High-dose 5-fluorouracil and leucovorin as second-line chemotherapy in patients with platinum resistant epithelial ovarian cancer. Cancer Chemother Pharmacol. 1995;37:190-2

14. Long HJ 3rd, Nelimark RA, Su JQ, Garneau SC, Levitt R, Goldberg RM, et al. Phase II evaluation of 5-fluorouracil and low-dose leucovorin in cisplatinrefractory advanced ovarian carcinoma. Gynecol Oncol. 1994;54:180-3.

15. Raymond E, Buquet-Fagot C, Djelloul S, Mester J, Cvitkovic E, Allain P, et al. Antitumor activity of oxaliplatin in combination with 5-fluorouracil and the thymidylate synthase inhibitor AG337 in human colon, breast and ovarian cancers. Anti-Cancer Drugs. 1997;8:876-85.

16. Goldberg RM, Sargent DJ, Morton RF, Fuchs CS, Ramanathan RK, Williamson SK, et al. A randomized controlled trial of fluorouracil plus leucovorin, irinotecan, and oxaliplatin combinations in patients with previously untreated metastatic colorectal cancer. J Clin Oncol. 2004;22:23-30. 
17. Pectasides D, Pectasides M, Farmakis D, Bountouroglou N, Nikolaou M, Koumpou $\mathrm{M}$, et al. Oxaliplatin plus high-dose leucovorin and 5- fluorouracil in pretreated advanced breast cancer: a phase II study. Ann Oncol. 2003;14: 537-42.

18. Kim YS, Hong J, Sym SJ, Park SH, Park J, Cho EK, et al. Oxaliplatin, 5-fluorouracil and leucovorin (FOLFOX-4) combination chemotherapy as a salvage treatment in advanced gastric cancer. Cancer Res Treat. 2010;42:24-9.

19. Sundar S, Symonds RP, Decatris MP, Kumar DM, Osman A, Vasanthan S, et al. Phase II trial of oxaliplatin and 5-fluorouracil/leucovorin combination in epithelial ovarian carcinoma relapsing within 2 years of platinum-based therapy. Gynecol Oncol. 2004;94:502-8.

20. Pectasides D, Pectasides M, Farmakis D, Gaglia A, Koumarianou A, Nikolaou $\mathrm{M}$, et al. Oxaliplatin plus high-dose leucovorin and 5-fluorouracil (FOLFOX 4) in platinum-resistant and taxane-pretreated ovarian cancer: a phase II study. Gynecol Oncol. 2004:95:165-72.

21. Rosa DD, Awada A, Mano MS, Selleslags J, Lebrun F, Gil T, et al. Oxaliplatin/ 5fluorouracil-based chemotherapy was active and well tolerated in heavily pretreated patients with ovarian carcinoma. Arch Gynecol Obstet. 2008;278: 457-62.

22. Lee HJ, Kim HS, Park NH, Chung HH, Kim JW, Song YS. Feasibility of oxaliplatin, leucovorin, and 5-fluorouracil (FOLFOX-4) chemotherapy in heavily pretreated patients with recurrent epithelial ovarian cancer. Cancer Res Treat. 2013;45:40-7.

23. Eisenhauer EA, Therasse P, Bogaerts J, Schwartz LH, Sargent D, Ford R, et al. New response evaluation criteria in solid tumours: revised RECIST guideline (version 1.1). Eur J Cancer. 2009:452:228-4

24. Rustin GJ, Vergote I, Eisenhauer E, Pujade-Lauraine E, Quinn M, Thigpen T, et al. Definitions for response and progression in ovarian cancer clinical trials incorporating RECIST 1.1 and CA 125 agreed by the gynecological Cancer Intergroup (GCIG). Int J Gynecol Cancer. 2011;21:419-23.

25. Cancer Therapy Evaluation Program. Common terminology criteria for adverse events, version 3.0 [Internet]. Bethesda: National Cancer Institute; 2003 [cited 2012 Nov 1]. Available from: http://ctep.cancer.gov/forms/ CTCAEv4.pdf

26. Conteduca V, Kopf B, Burgio SL, Bianchi E, Amadori D, De Giorgi U. The emerging role of anti-angiogenic therapy in ovarian cancer (review). Int J Oncol. 2014:44:1417-24.

27. Cancer Genome Atlas Research Network. Integrated genomic analyses of ovarian carcinoma. Nature. 2011:474:609-15.

28. Hoeijmakers JH. DNA damage, aging, and cancer. N Engl J Med. 2009;361: $1475-85$.

29. Zhu Y, Zhou S, Liu Y, Zhai L, Sun X. Prognostic value of systemic inflammatory markers in ovarian Cancer: a PRISMA-compliant meta-analysis and systematic review. BMC Cancer. 2018;18(1):443.

30. Peng LH, Chen XY, Wu TX. Topotecan for ovarian cancer. Cochrane Database Syst Rev. 2008;2:CD005589.

Ready to submit your research? Choose BMC and benefit from:

- fast, convenient online submission

- thorough peer review by experienced researchers in your field

- rapid publication on acceptance

- support for research data, including large and complex data types

- gold Open Access which fosters wider collaboration and increased citations

- maximum visibility for your research: over $100 \mathrm{M}$ website views per year

At $\mathrm{BMC}$, research is always in progress.

Learn more biomedcentral.com/submissions 